\title{
Successful Percutaneous Intervention for Chronic Total Occlusion of Left Subclavian Artery
}

\author{
Vishwanath Hesarur ${ }^{1,2 *}$, Suresh V Patted ${ }^{1,2}$, Sanjay Porwal ${ }^{1,2}$, Sameer Ambar ${ }^{1,2}$ and Prasad MR ${ }^{1,2}$ \\ ${ }^{1}$ Department of Cardiology, Jawaharlal Nehru Medical College, KLE Academy of Higher Education and Research, India \\ ${ }^{2}$ KLES Dr. Prabhakar Kore Hospital and Medical Research Centre, India
}

Submission: January 02, 2018; Published: March 09, 2018

*Corresponding author: Vishwanath Hesarur, Department of Cardiology, Jawaharlal Nehru Medical College, KLE Academy of Higher Education and Research, Deemed to be University, Belagavi, Karnataka India, Tel: +919480008361; Email: drvishwanathhesarur@yahoo.com

Abstract

Introduction: Subclavian artery stenosis is most commonly caused by atherosclerotic disease. Surgical treatment is associated with high morbidity and mortality. Intervention is generally reserved for the management of symptomatic patients who present with upper limb ischemia, Vertebrobasilar symptoms and subclavian steal syndrome. Endovascular stenting is preferred over surgery because of high success rate, less invasive and minimal complications.

Case report: Here we report a case of 56 year old female patient with history of hypertension and diabetes presented with dizziness, vertigo and left arm claudication with use of her left upper extremity since last six months. She was diagnosed as a case of subclavian steal syndrome.

Treatment: Patient underwent successful Percutaneous Transluminal Angioplasty (PTA) of the left subclavian artery with marked improvement of symptoms at follow-up. Patient was monitored with Duplex ultrasound of left subclavian artery, measurement of BP and examination of pulse at each visit.

Conclusion: PTA is an effective with high success rate, less invasive and minimal complications when compared to surgery for the treatment of symptomatic subclavian artery stenosis. However, regular clinical and Duplex ultrasound assessment of subclavian artery is necessary after angioplasty for monitoring restenosis.

Keywords: Subclavian steal syndrome (SSS); Percutaneous transluminal angioplasty (PTA); Subclavian artery stenosis; Intervention; Atherosclerotic disease

\section{Introduction}

Subclavian artery stenosis is most commonly caused by atherosclerotic disease. Stenosis typically occurs in the first part of the subclavian artery proximal to the origin of the vertebral artery extending from the ostium to the origin of the vertebral artery. The incidence of left subclavian artery stenosis is far higher than that of right subclavian artery stenosis.

Intervention is generally reserved for the management of symptomatic patients who present with upper limb ischemia, Vertebrobasilar symptoms and subclavian steal syndrome. Endovascular stenting is preferred over surgery because of high success rate, less invasive and minimal complications. Here we report a case of 56 year old female patient presented with subclavian steal syndrome whom we successfully treated with percutaneous transluminal angioplasty (PTA).

\section{Case Report}

A 56 year old female patient with history of hypertension and diabetes presented with dizziness, vertigo and left arm claudication with use of her left upper extremity since last six months.

\section{On physical examination}

Inability to measure BP on left arm with absent left radial pulse and right upper limb BP was 160/80 mmHg. There were no signs of ischemia in left upper extremity.

\section{Investigations}

Electrocardiogram showed sinus rhythm with no ST-T changes, Transthoracic echocardiography revealed good biventricular 
function with type 1 diastolic dysfunction. Coronary angiography showed mild single vessel disease. Aortic arch angiography and selective left subclavian angiography revealed total occlusion of left ostio-proximal subclavian artery (Figure 1).

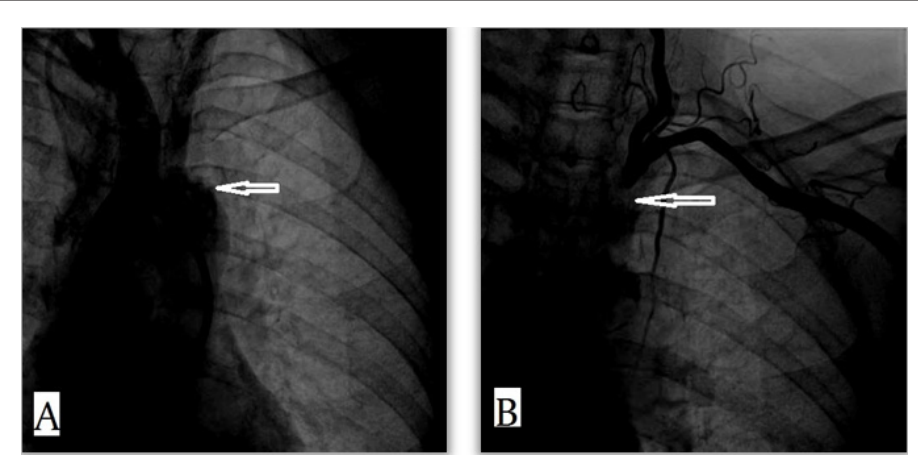

Figure 1: Aortic arch angiography (A) and selective left subclavian artery (B) showing total occlusion (arrow) of left ostio-proximal subclavian artery.

\section{Procedure}

The procedure was performed under local anaesthesia. The right femoral artery and left brachial artery were accessed percutaneously with $8 \mathrm{~F}$ and $6 \mathrm{~F}$ introducer sheaths, respectively. A preprocedural loading dose of Aspirin $325 \mathrm{mg}$ and $600 \mathrm{mg}$ of clopidogrel was given. Intravenous heparin $100 \mathrm{IU} / \mathrm{kg}$ and antibiotic were given.

Ostia of left subclavian artery was engaged by using JR 7F guiding catheter. Check angio showed total occlusion. A $6 \mathrm{~F}$ shuttle sheath was used to cannulate the vessel and placed distal to the occlusion. The lesion was crossed retrogradely using $0.014 \times 190 \mathrm{~cm}$ cross-it 200 and placed in proximal descending aorta (Figure 2A). Lesion was predilated using $3.5 \times 15 \mathrm{~mm}$ balloon at 8atm pressure (Figure 2B). Check angiogram through JR guiding catheter established good antegrade flow with no dissection (Figure 2C). Using another $0.014 \times 180 \mathrm{~cm}$ BMW wire crossed the lesion antegradely and the cross-it 200 wire removed (Figure 2D). An $8 \times 32 \mathrm{~mm}$ INVATEC scuba stent was deployed across ostioproximal subclavian artery (Figure 2E) with a good angiographic result (Figure 2F).
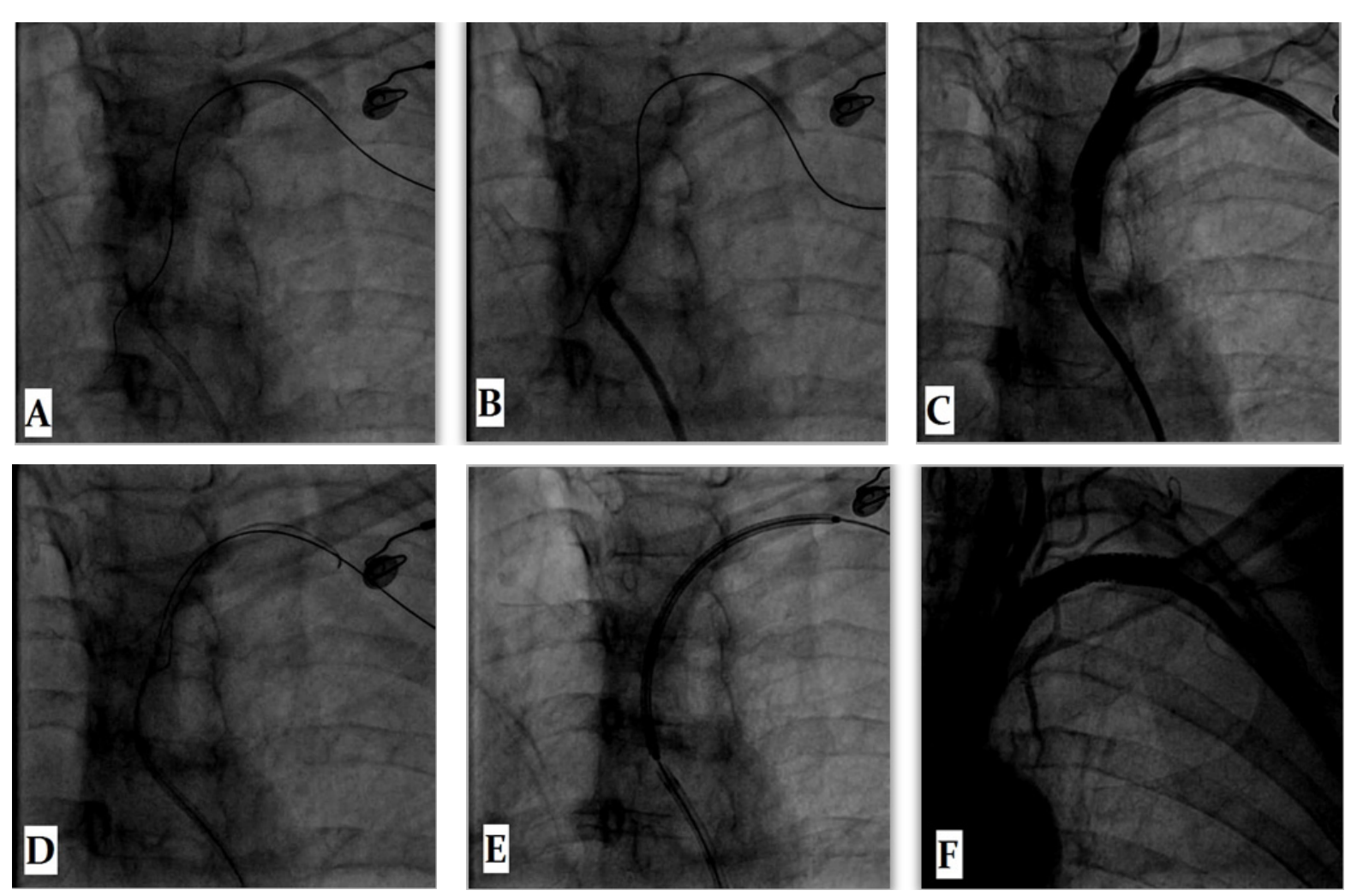

Figure 2: A: Lesion crossed retrogradely, B: Predilatation of lesion, C: Good antegrade flow, D: BMW wire crossed antegradely, E: Stent Placement and and F: Final result. 
Post procedure course was uneventful. The patient was discharged after three days with Aspirin 150mg OD, Clopidogrel $75 \mathrm{mg}$ BD and Rosuvastatin 40mg OD.

\section{Follow-up}

Patient was followed up at 1, 3, 6 months and one year. Patient reported marked improvement of symptoms. At each visit, patient was monitored with Duplex ultrasound of left subclavian artery, measurement of BP and examination of pulse.

\section{Discussion}

Atherosclerosis is the most common cause of subclavian stenosis and, thus, steal syndromes, irrespective of the clinical manifestation [1-3]. However, other causes include large artery vasculitis, thoracic outlet syndrome, and stenosis after surgical repair of coarctation of aorta or tetralogy of Fallot.

The presence of subclavian stenosis is associated with increased total mortality (hazard ratio, 1.40) and cardiovascular disease mortality (hazard ratio, 1.57) [2] and with an increased risk of cerebrovascular ischemic events related to progressive carotid stenosis and compromised collateral pathways. Thus, subclavian artery stenosis is a cardiovascular risk marker and require aggressive secondary prevention.

Even asymptomatic subclavian artery stenosis is associated with increased risk of morbidity and mortality related to underlying atherosclerotic disease burden in other vascular beds [2-4]. Symptomatic patients with proximal subclavian artery occlusive disease can be successfully treated either surgically or percutaneously [5-12].

First case report of subclavian angioplasty was done by Bachman \& Kim [13]. After this report, percutaneous intervention of subclavian disease has grown persistently, becoming the mainstay of therapy. Balloon angioplasty and stenting can be performed when stenting is unlikely to compromise the vertebral circulation. Technical success of the percutaneous approach can be achieved in $>90 \%$, with 5 -year patency rates of $85 \%$ [12]. Complications during subclavian artery intervention are stroke $(<1 \%)$, dissection, access site complications (0-5\%) like hematoma formation, thrombosis and pseudoaneurysm formation.

The major long-term risk of subclavian artery intervention is restenosis. Stenting appears to have significantly reduced the rate of restenosis, from $15-20 \%$ with angioplasty to $0-10 \%$. The treatment for restenosis will depend on its etiology. Failure to cover the ostium or Inadequate stent expansion may be treated with repeat angioplasty and, sometimes, re-stenting. Alternatively, surgical revascularization using an extrathoracic approach (carotid-subclavian, axillo-axillary) is a reasonable option in a symptomatic patient who is an operative candidate.

\section{Conclusion}

PTA is an effective with high success rate, less invasive and minimal complications when compared to surgery for the treatment of symptomatic subclavian artery stenosis. However, regular clinical and duplex ultrasound assessment of subclavian artery is necessary after angioplasty for monitoring restenosis.

\section{Conflict of Interest}

The author(s) declare(s) that there is no conflict of interest regarding the publication of this paper.

\section{Informed Consent}

Written informed consent was obtained from patient for publication of this case report and accompanying images.

\section{References}

1. Ochoa VM, Yeghiazarians Y (2011) Subclavian artery stenosis: a review for the vascular medicine practitioner. Vasc Med 16(1): 29-34.

2. Aboyans V, Kamineni A, Allison MA, McDermott MM, Crouse JR, et al. (2010) The epidemiology of subclavian stenosis and its association with markers of subclinical atherosclerosis: the Multi- Ethnic Study of Atherosclerosis (MESA). Atherosclerosis 211(1): 266-270.

3. Labropoulos N, Nandivada P, Bekelis K (2010) Prevalence and impact of the subclavian steal syndrome. Ann Surg 252(1): 166-170.

4. Clark CE, Taylor RS, Shore AC, Ukoumunne OC, Campbell JL (2012) Association of a difference in systolic blood pressure between arms with vascular disease and mortality: a systematic review and metaanalysis. Lancet 379(9819): 905-914.

5. Rogers JH, Calhoun RF (2007) Diagnosis and management of subclavian artery stenosis prior to coronary artery bypass grafting in the current era. J Card Surg 22(1): 20-25.

6. Babic S, Sagic D, Radak D, Antonic Z, Otasevic P, et al. (2012) Initial and long-term results of endovascular therapy for chronic total occlusion of the subclavian artery. Cardiovasc Intervent Radiol 35(2): 255-262.

7. Burihan E, Soma F, Iared W (2011) Angioplasty versus stenting for subclavian artery stenosis. Cochrane Database Syst Rev 10: CD008461.

8. De Vries JP, Jager LC, Van den Berg JC, Overtoom TT, Ackerstaff RG, et al. (2005) Durability of percutaneous transluminal angioplasty for obstructive lesions of proximal subclavian artery: long term results. J Vasc Surg 41(1): 19-23.

9. Filippo F, Francesco M, Francesco R, Corrado A, Chiara M, et al. (2006) Percutaneous angioplasty and stenting of left subclavian artery lesions for the treatment of patients with concomitant vertebral and coronary subclavian steal syndrome. Cardiovasc Intervent Radiol 29(3): 348353.

10. Salam TA, Lumsden AB, Smith RB (1994) Subclavian artery revascularization: a decade of experience with extrathoracic bypass procedures. J Surg Res 56(5): 387-392.

11. Song L, Zhang J, Li J, Gu Y, Yu H, et al. (2012) Endovascular stenting vs. extrathoracic surgical bypass for symptomatic subclavian steal syndrome. J Endovasc Ther 19(1): 44-51.

12. Wang KQ, Wang ZG, Yang BZ, Yuan C, Zhang WD, et al. (2010) Longterm results of endovascular therapy for proximal subclavian arterial obstructive lesions. Chin Med J (Engl) 123(1): 45-50.

13. Bachman DM, Kim RM (1980) Transluminal dilatation for subclavian steal syndrome. AJR Am J Roentgenol 135(5): 995-996. 
(C) This work is licensed under Creative

(C) BY $10.19080 /$ JOCCT.2018.09.555769
Your next submission with Juniper Publishers will reach you the below assets

- Quality Editorial service

- Swift Peer Review

- Reprints availability

- E-prints Service

- Manuscript Podcast for convenient understanding

- Global attainment for your research

- Manuscript accessibility in different formats

( Pdf, E-pub, Full Text, Audio)

- Unceasing customer service

Track the below URL for one-step submission https://juniperpublishers.com/online-submission.php 